\title{
Reproductive state affects hiding behaviour under risk of predation but not exploratory activity of female Spanish terrapins
}

\author{
Alejandro Ibáñez ${ }^{\mathrm{a}}{ }^{*}$, Alfonso Marzal $^{\mathrm{b}}$, Pilar López ${ }^{\mathrm{a}}$, José Martín ${ }^{\mathrm{a}}$ \\ ${ }^{\mathrm{a}}$ Departamento de Ecología Evolutiva, Museo Nacional de Ciencias Naturales, CSIC, \\ José Gutiérrez Abascal 2, E-28006 Madrid, Spain E-mail: alexibanez@mncn.csic.es \\ (A.Ibáñez) \\ ${ }^{b}$ Departamento de Biología Animal, Universidad de Extremadura, 06071 Badajoz, \\ Spain
}

\section{ABSTRACT}

Female investment during reproduction may reduce survivorship due to increased predation risk. During pregnancy, gravid females might diminish their locomotor performance due to the additional weight acquired. In addition, egg production may also increase thermoregulatory, metabolical and physiological costs. Also, pregnant females have greater initial fitness and should take fewer risks. Thus, females should consider their reproductive state when deciding behavioural responses under risky situations. Here, we examined how reproductive state influenced risk-taking behaviour under different contexts in female Spanish terrapins (Mauremys leprosa). We simulated predatory attacks of different risk level and measured the time that the turtles spent hiding entirely into their own shells (i.e. appearance times) and the subsequent time after emergence from the shell that the turtles spent immobile monitoring for predators before starting to escape actively (i.e. waiting times). We also performed a novelenvironment test and measured the exploratory activity of turtles. Results showed that, appearance, waiting and exploratory behaviour were not related among them, but appearance times were related among risk levels. In addition, only appearance times were affected by reproductive state. Thus, gravid females appeared relatively later from their shells after a predator attack than non-gravid ones. Moreover, within gravid females, those carrying greater clutches tended to have longer appearance times. This suggests that only larger clutches could affect hiding behaviour in risky contexts. In contrast, waiting time scanning for predators and exploratory activity were not affected by the reproductive state. Differences between gravid and non-gravid females might be 
explained by metabolic-physiological costs associated with egg production and embryo maintenance, as well as by the relatively higher immediate fitness of gravid females.

Keywords: Risk-taking, Hiding behaviour, Exploratory behaviour, Predation risk, Reproductive state

\section{Introduction}

One major concern in ecological studies is how to estimate the costs derived of reproduction (Renzick, 1985, 1992). Costs of reproduction may occur in fecundity, survival or both (Bell, 1980; Brodie, 1989; Landwer, 1994; Shine, 1980). With respect to survival costs, optimality models predict that prey with greater initial fitness should be more cautious against predators (Cooper and Frederick, 2007). This matches the “asset-protection principle” (Clark, 1994) that predicts that individuals with lower fitness will tend to take higher risks than those with higher fitness that will take fewer risks, which would become asset protecting.

The cost of reproduction is defined as the negative trade-off between current reproductive investment and future reproductive output (Reznick, 1985; Roff, 1992; Stearns, 1992). In this way, current reproductive effort might represent a cost of reproduction expressed, for example, as diminished locomotor performance and lowered survivorship to the next clutch (Miles et al., 2000). In reptiles, some studies have suggested that decreased locomotor capacities of gravid females could be due to the additional weight of the clutch (Shine, 1980; Van Damme et al., 1989). Nevertheless, locomotor impairment of gravid females might be also due to physiological changes associated to pregnancy rather than a direct effect of physical burden (Brodie, 1989; Olsson et al., 2000). Gravid females may also shift their behaviour independently of an increased weight (Cooper et al., 1990; Schwarzkopf and Shine, 1992). Along the same lines, because, in ectotherms, body temperatures before ovoposition influence developmental rates as well as phenotypic traits of the resultant offspring (Shine, 2006), gravid females require basking at higher frequencies and for longer periods to reach optimal temperatures for a correct embryo development (Blázquez, 1995; Braña, 1993; Brent Charland and Gregory, 1995). On the other hand, energy reserves allocated to reproduction might be important in terms of fecundity 
(Doughty and Shine, 1998). Metabolic rates tend to increase during gestation in pregnant female lizards due to embryogenesis (Angilletta and Sears, 2000; Robert and Thompson, 2000). In the same way, egg load occupies a great part of body cavity that might compress internal organs as lungs incurring on high energetic cost of breathing (Munns, 2013). Thus, switching behaviour in risky situations associated to gravidity in females might be also driven by thermoregulatory, metabolical and physiological requirements derived of egg production.

Our main aim here was to test whether reproductive state of female terrapins Mauremys leprosa imposes a cost in their risk-taking behaviour (i.e. antipredatory hiding responses into their shells) and/or exploratory behaviour in a novel environment. This is a predominantly aquatic turtle that remains most of the time submerged in water, but that needs to bask and nest in terrestrial habitats (Andreu and López-Jurado, 1998). Turtles usually bask during long periods until they detect any potential predator and quickly dive into water reducing the probability to be captured (López et al., 2005). The main turtle predators of this species come from terrestrial environments, basically mammals and birds (Martín and López, 1990). We simulated in the laboratory predatory attacks under different levels of risk and measured the hiding response of gravid and non gravid female turtles inside their shells. We also measured the exploratory activity of female turtles in a novel environment. Because these turtles may assess risk level and predator persistence after a simulated attack (Martín et al., 2005; Ibáñez et al., 2014), we expected that gravid females should modulate their hiding behaviour after the predator attack by considering their higher costs, in comparison with non-gravid females, in terms of performance, thermoregulation and/or metabolism. In addition, gravid females have higher current reproductive value and they should act more cautiously than non-gravid ones (Clark, 1994; Cooper and Frederick, 2007). Thus, we predicted that gravid females should spent longer times hidden inside their shells until they decide to switch and escape actively to a safer refuge. In the same way, we also predicted that reproductive state should affect exploratory activity behaviour in a novel environment. We expected that gravid females should be less explorative than nongravid ones due to their lower degree of mobility and more constrained thermoregulation and metabolism. However, alternatively, we could expect the opposite pattern because the reduced manoeuvrability of gravid females could force them to increase their inspective behaviour to obtain detailed information of the surroundings and have a successful escape of possible predators (Frommen et al., 2009). 


\subsection{Material and methods}

\subsection{Animals of study and husbandry}

We captured 20 adult female $M$. leprosa turtles during spring 2011 in several small streams, ponds and tributaries of the Guadiana River located within dehesa oaklands (Alconchel and Olivenza, Badajoz province, SW Spain). We used a modified version of the traditional underwater funnel traps, which include a mesh chimney that reaches from the body of the trap to the surface allowing the turtles to come to the surface to breath ( $\mathrm{T}$ and L Netmaking, Mooroolbark, Victoria, Australia; Kuchling 2003). We baited traps with sardines and protected them from terrestrial predators by waiting in the proximity. We revised the traps every hour to collect turtles. All collected turtles were alive and did not show any sign of being stressed inside the traps.

Turtles were transported in plastic cages ( $80 \times 40 \mathrm{~cm}$ and $50 \mathrm{~cm}$ height) to "El Ventorrillo" Field Station, near Navacerrada (Madrid province) where experiments were conducted. The journey was made by car with a duration of four hours while maintaining a constant temperature of $23^{\circ} \mathrm{C}$ to avoid heat stress. Turtles were housed in individual outdoor plastic aquaria (60 x $40 \mathrm{~cm}$ and $30 \mathrm{~cm}$ height) containing water and rocks that allow turtles to bask out of water. The photoperiod and temperature were the same as those of the surrounding area. Turtles were fed three times a week minced meat, earthworms, and a commercial compound of turtle "pellets". Turtles were held in captivity and the investigator minimized contact with the animals before and during all behavioural experiments to avoid possible effects of habituation. All individuals were healthy and in good condition during the tests, and at the beginning of August, when the experiments had finished, turtles were returned to the exact locations of capture.

\subsection{Reproductive state, size and body condition of females}

In turtles, X-ray photographs have been effectively used to directly evaluate clutch size (Gibbons, 1982; Gibbons et al., 1982; Iverson, 1991). This technique allows reproductive data to be gathered in a non-destructive manner (Gibbons and Greene, 1979). Thus, we used direct digital X-ray photography (Direct Digital System, SEDECAL) to determine gravity state of female turtles. Turtles were x-rayed on their 
abdomen, where the absence or the entire clutch of eggs could be seen on a single plate (gravid: $N=7$; non-gravid: $N=13$; egg load of gravid females: mean $\pm 1 \mathrm{SE}=8.1 \pm 0.6$ eggs, range $=6-10)$.

We used a metal ruler (1 mm precision) to measure carapace length (CL) as the greatest straight-line distance from the anterior end to the posterior end of the shell (mean $\pm 1 \mathrm{SE}=190 \pm 3 \mathrm{~mm}$, range 168-209 mm). We used a Pesola spring scale to measure body weight (mean $\pm 1 \mathrm{SE}=952 \pm 40 \mathrm{~g}$, range $=680-1,300 \mathrm{~g})$.

\subsection{Hiding behaviour}

We simulated predatory attacks towards individual turtles $(N=20)$ in outdoor conditions always in sunny days (approximately $25^{\circ} \mathrm{C}$ ). For the 'low risk' treatment, we took one turtle from its home cage, handled it once, briefly (approx. 20 s) and gently, and then released it prone in the middle of an open field with short grass. To avoid other confounding effects that may affect risk perception of turtles (Burger and Gochfeld, 1993; Cooper, 1997; Cooper et al., 2003), the same person wearing the same clothing performed all tests following the same procedure. Turtles were used only once in each trial to avoid stress; the trials were spaced sufficiently (at least 1 day) so that fatigue resulting from one test did not affect subsequent tests. Before the trials, we allowed turtles to bask in their outdoor home cages for at least $2 \mathrm{~h}$, which allowed them to attain and maintain an optimal body temperature within the activity and preferred temperature range of the species (Andreu and López-Jurado, 1998; Keller and Busack, 2001).

After the simulated attacks, the experimenter retreated and remained immobile observing with binoculars from a hidden position situated $5 \mathrm{~m}$ far from the turtle. After the simulated attack, and as a consequence of handling, turtles typically remained immobile and withdrawn entirely into the shell (i.e. the head, legs and tail were not or were only barely visible from above the carapace). We then measured the time that the turtle spent withdrawn into the shell, since we released it on the ground until the head emerged from the shell (i.e. when the eyes could be seen from above the shell; 'appearance time'), and the time from appearance until the turtle emerged entirely from the shell and started to escape actively (i.e. when the turtle first touched the ground with the limbs or head) ('waiting times'). We chose these two times for posterior analyses because 'appearance times"” represented a situation where the turtles had no visual 
information on the predator or the surrounding habitat (Martín et al., 2005; Ibáñez et al., 2014). However, during 'waiting times'” turtles were able to check visually their surroundings to monitor the presence of the predator and evaluate when to switch to an active escape (Martín et al., 2005; Ibáñez et al., 2014).

\subsection{Hiding behavior when the turtle was turned over onto its carapace by the predator}

In this experiment ('high' risk' treatment), we followed the same procedure as above, but we took the turtle $(N=20)$ from their own aquaria and walked and tapped gently the turtle with the hand during 5 min, simulating that a predator had captured it, before releasing the turtle placed onto their carapace with the plastron upside in the grass field. We, thus, simulated a predator that had turned over the turtle to prevent it from escaping and, thus, attack it more easily. This is a higher risk situation because in this position a turtle could not walk but, before escaping, it had to extend its legs and neck entirely outside of the shell, and use them to turn itself back to its normal position. We monitored 'appearance time' (i.e. when the head emerged from the carapace and the eyes could be seen from above) and 'waiting time' from then until the turtle first touched the ground with the limbs or head.

\subsection{Exploratory activity behaviour}

We performed a novel-environment test in indoor conditions to assess the exploratory activity behaviour of female turtles in a glass cage $(100 \times 50 \times 50 \mathrm{~cm})$, which surface was divided in six equally sized rectangle areas (33 x $25 \mathrm{~cm}$ ). The experimental room was lit with fluorescent lights and the temperature was the same than the surroundings (approximately $25^{\circ} \mathrm{C}$ ). The cage contained a sand substrate, thus, simulating a terrestrial habitat, which is subjected to higher risk than an aquatic one (Martín et al., 2005; Polo-Cavia et al., 2008; Ibáñez et al., 2014), and providing excellent traction for the turtle movements. We gently took a turtle from its outdoor home cage, and released it on one of the corners of the experimental cage, always in the same position and orientation. The experimenter subsequently retreated and observed from a partially hidden position monitoring constantly the position of the turtle. Usually turtles spent some time remaining withdrawn into their shells until they put out the head and limbs and started to walk around the cage. Then, we measured the time spent until 
the turtle moved to another division of the cage (i.e. when crossed the divisory line for first time) ('latency time') and the total number of changes between divisions or the total number of crossed lines ('activity'). Every trial had a maximum duration of 10 min. In a few cases (3 of 20 trials) the turtle did not move from the initial square during the total observation period and, then, we assigned $10 \mathrm{~min}$ for the variable 'latency time‘ and zero for the variable 'activity'.

\subsection{Statistical analyses}

To summarise the six variables describing risk-taking behaviour (i.e. hiding behaviour) under the two risk levels and exploratory activity behaviour of turtles we used a principal component analysis (PCA) with a Varimax rotation (Table 1). Then, we performed General Linear Models (GLMs) with the PC-scores values from this PCA as dependent variables, carapace length as a continuous variable (covariate) and reproductive state (gravid vs. non-gravid) of turtles as a fixed factor.

\section{Results}

\subsection{Hiding and exploratory behaviour}

Values of the hiding and exploratory behavioural variables of turtles measured in the experiment are given in Table 1. The PCA for these measurements produced three independent components that together accounted for $77 \%$ of the variance. The first PC $(\mathrm{PC} 1$; eigenvaluse $=1.78, \%$ Variance $=29.7 \%)$ was correlated with exploratory activity behaviour in a novel environment; negatively with the variable describing longer times until the turtles initiated the first movement $(r=-0.93)$, and positively with the variable describing a greater number of changes between divisions of the aquarium ( $r=0.87$ ). Thus, PC1 described a gradient from less exploratory turtles, with longer latency times until the first movement and lower activity in a novel environment, to more exploratory turtles, with shorter latency times and higher activity. The second PC (PC2; eigenvaluse $=1.67, \%$ Variance $=27.8 \%$ ) was positively correlated with variables describing longer appearance times from inside the shell after a simulated attack in both low and high risk treatments ( $r=0.92$ in both cases). Thus, PC2 described a gradient from turtles that were more likely to take risk by spending shorter times 
hidden into their shells to turtles less likely to take risk that spent longer times hidden after a simulated attack. The third PC $(\mathrm{PC} 3$; eigenvalue $=1.17, \%$ Variance $=19.5 \%)$ was related with waiting times across the two risk levels, positively with waiting times of turtles until they decided to escape under low risk $(r=0.68)$ and negatively with waiting times under 'high risk $(r=-0.93)$. Thus, PC3 described a gradient from turtles having shorter waiting times in the low risk treatment but longer waiting times under high risk.

The results of the PCA showed that there was a positive correlation between the appearance times during low risk treatment (when the turtle was prone) and during high risk treatment . Thus, females that were risk-prone with respect to time hidden in the shell after appearance in the low risk treatment were also risk-prone in the high risk treatment. In contrast, turtles that were risk-prone with respect to waiting times under low risk were risk-averse under high risk and viceversa. Otherwise, with respect to exploratory behaviour, there was a negative correlation between the first time that a turtle crossed a line (latency time) and the total number of crossed lines (exploratory activity) in a novel environment . Thus, turtles that initiated their exploration earlier also had a higher activity level. On the other hand, the separation of appearance, waiting and exploratory behaviour in different independent PCs indicated that these behaviours were not related among them.

\subsection{Effect of females' reproductive state on hiding and exploratory behaviour}

Gravid and non-gravid females did not significantly differ in carapace length (GLM: $F_{1,18}=0.31, p=0.58$; gravid: mean $\pm \mathrm{SE}=188 \pm 5 \mathrm{~mm}$; non-gravid $=191 \pm 3$ $\mathrm{mm}$ ) or weight (GLM: $F_{1,18}=0.71, p=0.41$; gravid: mean $\pm \mathrm{SE}=905 \pm 19 \mathrm{~g}$; nongravid= $977 \pm 14 \mathrm{~g}$ ). Similarly, reproductive state did not affect the relative weight of the females (GLM with carapace length as covariate; $F_{1,17}=1.18, p=0.29$ ). Clutch size was significantly and positively related with body mass in gravid females (Spearman correlation, $\left.r_{s}=0.76, t_{5}=2.65, p=0.046\right)$.

Furthermore, results showed that some components of risk taking behaviour of female turtles (described by the PC scores obtained from the PCA) were affected by reproductive state. PC2 scores were significantly affected by reproductive state (GLM with carapace length as a covariate; $F_{1,17}=4.84 ; p=0.04$; partial eta-squared $=0.22$; Fig. 1b). Thus, gravid turtles had significantly longer appearance times from inside their 
shells (i.e. higher PC2 scores) than non-gravid females. In contrast, reproductive state did not affect waiting times (i.e. PC3 scores) (GLM with carapace length as a covariate; $F_{1,17}=2.28 ; p=0.15$; partial eta-squared $=0.12$; Fig. 1c).

Exploratory behaviour described by PC1 scores was not significanlty affected by reproductive state (GLM with carapace length as a covariate; $F_{1,17}=0.08 ; p=0.78$; partial eta-squared $=0.004$; Fig. 1a).

Clutch size was not significantly related with exploratory behaviour of the turtles (Spearman correlation: PC1, $r_{s}=-0.05, t_{5}=-0.12, p=0.90$ ). Nevertheless, clutch size tended, although not significantly, to affect both appearance times (Spearman correlation: PC2; $\left.r_{s}=0.67 t_{5}=2.03 p=0.09\right)$ and waiting times $\left(\mathrm{PC} 3 ; r_{s}=0.69, t_{5}=\right.$ 2.13, $p=0.08$ ) of gravid females.

\section{Discussion}

Our results revealed three different independent axis for risk-taking and exploratory behaviour of female Spanish terrapins. Thus, there is no indication on a possible phenotypic correlation between risk-taking behaviour and exploration in a new environment in this turtle. Thus, turtles that were more willing to take risks in a novel environment initiated their activity relatively faster and changed more often between parts of the experimental cage. In addition, appearance and waiting times seemed to be two independent components of the hiding behaviour inside their shell of the turtles in response to a predatory attack. Appearance times represent the time till a turtle decide to emerge from a refuge where they do not have information of the surroundings (Martín et al., 2005; Ibáñez et al., 2014). However, during waiting times to monitor the surroundings, turtles have to place out of the shell their colourful head and limbs, increasing the probability of being detected by predators (Ibáñez et al., 2013, 2014). More risk-prone turtles spent shorter appearance in both risk levels. However, turtles that spent longer waiting times monitoring the surroundings in the low risk treatment spent shorter waiting times monitoring when risk increased. This could be explained by the higher uncertainty on the predator presence and intentions in the low risk sitiation, which requires longer monitoring times (Polo et al., 2011).

The results obtained in the present study suggest that appearance times could potentially form a personality trait in female Spanish terrapins. The finding in other taxa have shown that differences in risk-taking behaviour are stable over time, thereby 
giving rise to animal personalities (Biro and Stamps, 2008; Réale et al., 2007; Wolf et al. 2007; ). For example, individual adult male Iberian rock lizards (Iberolacerta cyreni) were consistent in their relative levels of refuge use under different levels of risk (López et al., 2005). Similarly, in great tits (Parus major) risk-taking behavior was repeatable and heritable between generations (Van Oers et al., 2004). However, our results are only suggestive because we could not estimate between- and within-individual variation in appearance times due to the low power (we had only two repetitions) and, thus, we could not conclude the existence of a consistent personality trait (Dingemanse and Dochtermann, 2013).

Female turtles appearance times' during both low and high risk treatments were affected by their reproductive state, with gravid females having longer appearance times than non-gravid females. In addition, gravid females carrying greater clutches tended to appear relatively later from inside their shells than those carrying fewer eggs. However, waiting times were not affected by female reproductive state, although gravid females with more eggs tended to have longer waiting times in low risk and shorter waiting times in high risk level. The differences in appearance times between gravid and non-gravid females might be attributed to the trade off between current and future reproductive effort. The current reproductive value of gravid females is much higher than that of non-gravid ones. The "asset-reproductive principle” predicts that the larger an individual's current reproductive value, the more important it becomes that the asset be protected (Clark, 1994). This principle occurs in many animal systems. For example, in juvenile salmon (Oncorhynchus kisutch) the negative correlation between body size and risk taking is an example of asset protection, whereby larger animals accept less predation risk to protect their greater accumulated fitness value (Reinhardt and Healey, 1999). Also, future fitness has important consequences for variation in a risky behaviour such as helping effort, in eusocial wasps (Field and Cant, 2009). In the same way, gravidity in females may reduce the likelihood of risky behaviour. In the marine snail (Littorina saxatilis) gravid females with a higher number of embryos appear to remain more time in shelters, suggesting that those snails with more to lose are those more likely to avoid risk (Pardo and Johnson, 2006). Similarly, in sea snakes (Laticauda spp.), gravid females ceased to feed due to the risks entailed in foraging activity (Brischoux et al., 2011). Thus, because gravid females of $M$. leprosa invested relatively more in current reproduction than non-gravid ones, gravid females should be more cautiously when facing a 
potential predator attack, which may explain their relatively longer hiding times (Cooper and Frederick, 2007).

On the other hand, gravidity may impose mechanical limitations for an active escape strategy due to the weight of a clutch of eggs reduces their maximum running speed (Cooper et al., 1990; Shine, 1980). Egg mass may represent a high percentage of the overall female body mass in freshwater turtles (Congdon et al., 1986). However, similar to other study with lizards, in our study gravid and non-gravid females did not differ in weight although gravid females had less risky behaviour (Downes and Bauwens, 2002). Thus, alternatively or in addition to the burden of egg weight, other factors may explain antipredatory behaviour shift in gravid female turtles. In other reptiles, such as sea turtles, females lipid reserves are maximal before breeding during vitellogenic process for follicular development, while plasma triglycerides decrease towards the end of nesting season suggesting that a decrease in energy resources is one of the main factors involved in the regulation of the reproduction (Hamann et al., 2002). Similarly, in the freshwater turtle Emydura krefftii a steady decline in the fat stores coincided with the period of follicular development in breeding females (Georges, 1983).This decline in available triglycerides and fat stores associated with reproduction might compromise the energy available for escape strategies in gravid terrapins. Nevertheless, the trend observed in gravid females in our study suggests that greater clutches (carried by large females) could also affect appearance and waiting times. In agreement, in female zebra finches an increase of egg production entailed a detriment in escape flight performance mediated through flight muscle loss rather than changes in body mass (Veasey et al., 2001). Similarly, gravid female turtles might be less risk prone than non-gravid females due to a detrainment in their physical condition associated to egg production rather than weight differences per se. Alternatively, the higher bask requirements of gravid females could increase the probability of detection by predators (Downes and Bauwens, 2002). In fact, turtles often bask during long periods near water and escape diving to water before they could be visually detected by the observer (López et al., 2005). In addition, the rate of oxygen consumption tends to increase with the number of embryos carried by the female suggesting that the metabolic costs increase according with the number of eggs (Birchard et al., 1984). Thus, gravid turtles with more eggs could need to bask for longer periods as it happens in gravid lizards (Shine, 1980). In this way, gravid females with greater clutches could need longer appearance times and waiting times (under low risk) to reach an optimal 
temperature due to the higher requirements of egg production. Paradoxically, females carrying more eggs tended to have shorter waiting times under high risk probably because in this context the turtle have assumed that have been already detected by the predator rendering unimportant other traits.

Otherwise, explorative activity behaviour was not affected by reproductive state of the female turtles. Exploratory behaviour has been shown as hereditable and advantageous in some contexts, for example, in great tits (Parus major), faster exploratory parents had offspring with greater ability for dispersing in wild habitats (Dingemanse et al., 2003). Similarly, more exploratory lizards in a novel environment should enhance fast risk assessment abilities (Rodríguez-Prieto et al., 2011). However in our study, gravidity did not affect exploratory behaviour suggesting that this factor might be unimportant for exploration in new environments or that the effect might be masked by other factors. Nevertheless, our results could be limited by the fact that exploratory behaviour was assessed in a terrestrial environment while M. leprosa is mainly an aquatic turtle. Although activity in terrestrial environments is more risky, it might be more important for male terrapins at the beginning of the mating season, while females are less mobile (Andreu and López-Jurado, 1998) and, therefore, their terrestrial activity should be more limited. Further studies should assess exploratory behaviour in aquatic environments for a more complete approach.

However, our results must be taken carefully because the sample size in this study is low. This fact can lead to low statistical power therefore reducing the chances of finding an effect when one exist. However, in any case, the effect sizes reported for the models (see Results) suggest that there are large effect sizes for gravidity affecting appearance times. Even the arbitrary on defining the magnitude of effect sizes, larger values of effect sizes means greater degree of manifestation of the studied phenomena (Cohen, 1988).

In conclusion, gravid females appeared relatively later from into their shells after a predatory attack respect to non-gravid ones. These results may suggest that larger clutches could affect hiding behaviour in risky contexts of Spanish terrapin females. The lack of difference in relative and absolute weight between gravid and non-gravid females suggest that differences in appearance times might be due to metabolic-physiological costs and a worse condition of gravid females associated with egg production and embryo maintain. Additionally, gravid females may tend to take fewer risks to protect their immediate higher fitness respect to non-gravid ones. 
Nevertheless, further studies with more statistically power should clarify the evolution of the behavioural strategies in risky contexts and the relation with female reproductive state.

\section{Acknowledgements}

We thank one anonimous reviewer for helpful comments, J. Ortega and E. Fraile for supplying x-rays, A. Marzal and D. Martín for allowing us to work in their dehesa states ('La Asesera' and 'Cabeza Rubia'), A. González and M. González for field assistance, and 'El Ventorrillo' MNCN Field Station for use of their facilities. Financial support was provided by a MEC-FPI grant (reference: BES-2009-025228) to A.I. and by the project MICIIN-CGL201124150/BOS. Captures and experiments complied with all current laws of Spain and the Environmental Agency ('Consejería de Industria, Energía y Medio Ambiente’) of the 'Junta de Extremadura' Local Government (permit number: CN0008/11/ACA). Procedures conformed to recommended guidelines for use of live reptiles in laboratory research (ASIH 2004).

\section{References}

Andreu, A., López-Jurado, L., 1998. Mauremys leprosa (Schweigger, 1812). In: Salvador, A. (Ed.), Fauna Ibérica, Volumen 10. Museo Nacional de Ciencias Naturales, Consejo Superior de Investigaciones Científicas, Madrid, pp. 103-108.

Angilletta, M., Sears, M., 2000. The metabolic cost of reproduction in an oviparous lizard. Funct. Ecol. 14, 39-45.

ASIH, 2004. Guidelines for Use of Live Amphibians and Reptiles in Field and Laboratory Research. 2nd edn. Herpetological Animal Care and Use Committee (HACC) of the American Society of Ichthyologists and Herpetologists, Lawrence, Kansas.

Bell, G., 1980. The costs of reproduction and their consequences. Am. Nat. 116, 45-76.

Birchard, G.F., Black, C.P., Schuett, G.W., Black, V., 1984. Influence of pregnancy on oxygen consumption, heart rate and hematology in the garter snake: implications for the "cost of reproduction” in live bearing reptiles. Comp. Biochem. Physiol. A 77, 519-523.

Biro, P.A., Stamps, J.A., 2008. Are animal personality traits linked to life-history productivity? Trends Ecol. Evol. 23, 361-368. 
Blázquez, M.C., 1995. Body temperature, activity patterns and movements by gravid and nongravid females of Malpolon monspessulanus. J. Herpetol. 29, 264-266.

Braña, F., 1993. Shifts in body-temperature and escape behavior of female Podarcis muralis during pregnancy. Oikos 66, 216-222.

Brent Charland, M., Gregory, P.T., 1995. Movements and habitat use in gravid and nongravid female garter snakes (Colubridae: Thamnophis). J. Zool. 236, 543-561.

Brischoux, F., Bonnet, X., Shine, R., 2011. Conflicts between feeding and reproduction in amphibious snakes (sea kraits, Laticauda spp.). Austral Ecol. 36, 46-52.

Brodie, E.D., 1989. Behavioral modification as a means of reducing the cost of reproduction. Am. Nat. 134, 225-238.

Burger, J., Gochfeld, M., 1993. The importance of the human face in risk perception by black iguanas, Ctenosaura similis. J. Herpetol. 27, 426-430.

Clark, C.W., 1994. Antipredator behavior and the asset-protection principle. Behav. Ecol. 5, 159-170.

Cohen, J., 1988. Statistical Power Analysis for the Behavioral Sciences. Hillsdale, New Jersey: Erlbaum.

Congdon, J.D., Greene, J.L., Gibbons, J.W., 1986. Biomass of freshwater turtles: a geographic comparison. Am. Midl. Nat. 115, 165-173.

Cooper, W.E., 1997. Factors affecting risk and cost of escape by the broad-headed skink (Eumeces laticeps): Predator speed, directness of approach, and female presence. Herpetologica 53, 464-474.

Cooper, W.E., Frederick, W.G., 2007. Optimal time to emerge from refuge. Biol. J. Linn. Soc. 91, 375-382.

Cooper, W.E., Martín, J., López, P., 2003. Simultaneous risks and differences among individual predators affect refuge use by a lizard, Lacerta monticola. Behaviour $140,27-41$.

Cooper, W.E., Vitt, L.J., Hedges, R., Huey, R.B., 1990. Locomotor impairment and defense in gravid lizards (Eumeces laticeps): behavioral shift in activity may offset costs of reproduction in an active forager. Behav. Ecol. Sociobiol. 27, 153157.

Dingemanse, N.J., Both, C., Van Noordwijk, A.J., Rutten, A.L., Drent, P.J., 2003. Natal dispersal and personalities in great tits (Parus major). Proc. R. Soc. Lond. B. 270, 741-747. 
Dingemanse, N.J., Dochtermann, N.A., 2013. Quantifying individual variation in behaviour: mixed-effect modelling approaches. J. Anim. Ecol. 82, 39-54.

Doughty, P., Shine, R., 1998. Reproductive energy allocation and long-term energy stores in a viviparous lizard (Eulamprus tympanum). Ecology 79, 1073-1083.

Downes, S.J., Bauwens, D., 2002. Does reproductive state affect a lizard's behavior toward predator chemical cues? Behav. Ecol. Sociobiol. 52, 444-450.

Field, J., Cant, M. A., 2009. Social stability and helping in small animal societies. Proc. R. Soc. Lond. B. 364, 3181-3189.

Frommen, J., Mehlis, M., Bakker, T., 2009. Predator-inspection behaviour in female three-spined sticklebacks Gasterosteus aculeatus is associated with status of gravidity. J. Fish Biol. 75, 2143-2153.

Georges, A., 1983. Reproduction of the Australian freshwater turtle Emydura krefftii (Chelonia: Chelidae). J. Zool. 201, 331-350.

Gibbons, J.W., 1982. Reproductive patterns in freshwater turtles. Herpetologica 38, 222-227.

Gibbons, J.W., Greene, J.L., 1979. X-ray photography: technique to determine reproductive patterns of freshwater turtles. Herpetologica 35, 86-89.

Gibbons, J.W., Greene, J.L., Patterson, K.K., 1982. Variation in reproductive characteristics of aquatic turtles. Copeia 1982, 776-784.

Hamann, M., Limpus, C., Whittier, J., 2002. Patterns of lipid storage and mobilisation in the female green sea turtle (Chelonia mydas). J. Comp. Physiol. B 172, 485493.

Ibáñez, A., Marzal, A., López, P., Martín, J., 2013. Sexually dichromatic coloration reflects size and immunocompetence in female Spanish terrapins, Mauremys leprosa. Naturwiss. 100, 1137-1147.

Ibáñez, A., López, P., Martín, J., 2014. Inter-individual variation in antipredator hiding behavior of spanish terrapins depends on sex, size and coloration. Ethology 120, 742-752.

Iverson, J.B., 1991. Life history and demography of the yellow mud turtle, Kinosternon flavescens. Herpetologica 47, 373-395.

Keller, C., Busack, S.D., 2001. Mauremys leprosa (Schweigger, 1812) - Maurische Bachschildkröte. In: Fritz, U. (Ed.), Handbuch der Reptilien und Amphibien Europas. Schildkröten (Testudines) I. Aula, Wiebelsheim, Germany:, pp. 57-88. 
Kuchling, G., 2003. A new underwater trap for catching turtles. Herpetol. Rev. 34, 126128.

Landwer, A.J., 1994. Manipulation of egg production reveals costs of reproduction in the tree lizard (Urosaurus ornatus). Oecologia 100, 243-249.

López, P., Hawlena, D., Polo, V., Amo, L., Martín, J., 2005. Sources of individual shybold variations in antipredator behaviour of male Iberian rock lizards. Anim. Behav. 69, 1-9.

López, P., Marcos, I., Martín, J., 2005. Effects of habitat-related visibility on escape decisions of the Spanish Terrapin Mauremys leprosa. Amphib.-Rept. 26, 557-561.

Lourdais, O., Heulin, B., Denardo, D.F. 2008. Thermoregulation during gravidity in the children's python (Antaresia childreni): a test of the preadaptation hypothesis for maternal thermophily in snakes. Biol. J. Linn. Soc. 93, 499-508.

Mänd, T., Tammaru, T., Mappes, J., 2007. Size dependent predation risk in cryptic and conspicuous insects. Evol. Ecol. 21, 485-498.

Martín, J., López, P., 1990. Amphibians and reptiles as prey of birds in southwestern Europe. Smithson. Herpetol. Inf. Serv. 82, 1-43.

Martín, J., López, P., Cooper, W.E., 2003. Loss of mating opportunities influences refuge use in the Iberian rock lizard, Lacerta monticola. Behav. Ecol. Sociobiol. 54, 505-510.

Martín, J., Marcos, I., López, P., 2005. When to come out from your own shell: risksensitive hiding decisions in terrapins. Behav. Ecol. Sociobiol. 57, 405-411.

Miles, D.B., Sinervo, B., Frankino, W.A., 2000. Reproductive burden, locomotor performance, and the cost of reproduction in free ranging lizards. Evolution 54, 1386-1395.

Munns, S.L., 2013. Gestation increases the energetic cost of breathing in the lizard Tiliqua rugosa. J. Exp. Biol. 216, 171-180.

Olsson, M., Shine, R., Bak-Olsson, E., 2000. Locomotor impairment of gravid lizards: is the burden physical or physiological? J. Evol. Biol. 13, 263-268.

Pardo, L.M., Johnson, L.E., 2006. Influence of water motion and reproductive attributes on movement and shelter use in the marine snail Littorina saxatilis. Mar. Ecol. Prog. Ser. 315, 177-186.

Polo, V., López, P., Martín, J., 2011. Uncertainty about future predation risk modulates monitoring behaviour from refuges in lizards. Behav. Ecol. 22, 218-223. 
Polo-Cavia, N., López, P., Martín, J., 2008. Interspecific differences in responses to predation risk may confer competitive advantages to invasive freshwater turtle species. Ethology 114, 115-123.

Réale, D., Reader, S.M., Sol, D., McDougall, P.T., Dingemanse, N.J., 2007. Integrating animal temperament within ecology and evolution. Biol. Rev. 82, 291-318.

Reaney, L.T., 2007. Foraging and mating opportunities influence refuge use in the fiddler crab, Uca mjoebergi. Anim. Behav. 73, 711-716.

Reinhardt, U.G., Healey, M.C., 1999. Season-and size-dependent risk taking in juvenile coho salmon: experimental evaluation of asset protection. Anim. Behav. 57, 923933.

Reznick, D., 1985. Costs of reproduction: an evaluation of the empirical evidence. Oikos 44, 257-267.

Robert, K.A., Thompson, M.B., 2000. Energy consumption by embryos of a viviparous lizard, Eulamprus tympanum, during development. Comp. Biochem. Physiol. A 127, 481-486.

Rodríguez-Prieto, I., Martín, J., Fernández-Juricic, E., 2011. Individual variation in behavioural plasticity: direct and indirect effects of boldness, exploration and sociability on habituation to predators in lizards. Proc. R. Soc. Lond. B. 278, 266273.

Roff, D.A., 1992. The Evolution of Life Histories: Theory and Analysis. Chapman and Hall, New York.

Schwarzkopf, L., Shine, R., 1992. Costs of reproduction in lizards: escape tactics and susceptibility to predation. Behav. Ecol. Sociobiol. 31, 17-25.

Shine, R., 1980. “Costs” of reproduction in reptiles. Oecologia 46, 92-100.

Shine, R., 2006. Is increased maternal basking an adaptation or a pre-adaptation to viviparity in lizards? J. Exp. Zool. A. 305, 524-535.

Stearns, S.C., 1992. The Evolution of Life Histories. Oxford University Press, Oxford, England.

Van Damme, R., Bauwens, D., Verheyen, R.F., 1989. Effect of relative clutch mass on sprint speed in the lizard Lacerta vivipara. J. Herpetol. 23, 459-461.

Veasey, J. S., Houston, D.C., Metcalfe, N.B., 2001. A hidden cost of reproduction: the trade-off between clutch size and escape take-off speed in female zebra finches. J. Anim. Ecol. 70, 20-24. 
Wolf, M., Van Doorn, G.S., Leimar, O., Weissing, F.J., 2007. Life-history trade-offs favour the evolution of animal personalities. Nature 447, 581-584. 
Table 1. Values for the behavioural variables measured of the turtles when hiding into their shells in response to simulated predator attacks under two risk levels and when exploring a novel environment.

Gravid $(N=7)$

Behavioural variables

Appearance time low risk (s)

Appearance time high risk (s)

Waiting time low risk (s)

Waiting time high risk (s)

Latency time novel-environment (s)

Activity novel-environment ( $\mathrm{n}^{\mathrm{o}}$ lines)

Mean+SE Min-Max

Non-gravid $(N=13)$

Mean - SE Min-Max

$50.1+20.8 \quad 5-167$

231.0+93.7 18-745

$6.1+2.0$

$1-22$

$171.5+28.5 \quad 5-318$

$35.3 \pm 7.4 \quad 11-67$

$67.0+20.1$

$1-232$

$68.0+41.9 \quad 0-316$

$27.7 \pm 9.2$

0-100

215.0+95.1 17-600

$198.5+54.0 \quad 15-600$

$8.1+2.8$

$0-20$

$8.38+2.3$

0-31 
Figure 1. PC scores (Mean $\pm \mathrm{SE}$ showed) of female turtles depending on their reproductive state, a) PC1 (activity level), b) PC2 (appearance times) and c) PC3 (waiting times).
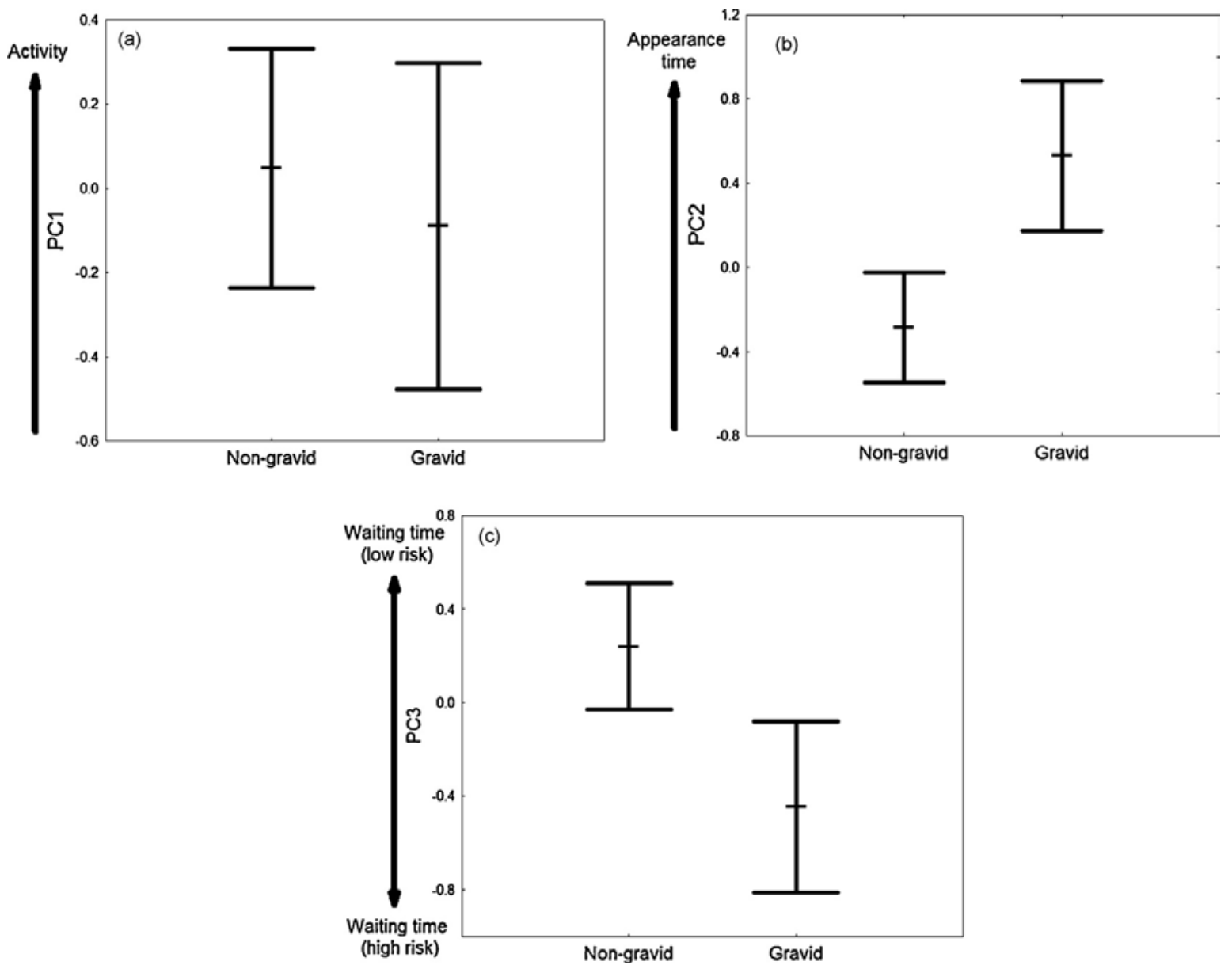